\section{(6) OPEN ACCESS}

\title{
Mortality rates by occupation in Korea: a nationwide, 13-year follow-up study
}

\author{
Hye-Eun Lee, ${ }^{1}$ Hyoung-Ryoul Kim, ${ }^{1}$ Yun Kyung Chung, ${ }^{2}$ Seong-Kyu Kang, ${ }^{3}$ \\ Eun-A Kim ${ }^{4}$
}

${ }^{1}$ Department of Occupational and Environmental Medicine, College of Medicine,

The Catholic University of Korea, Seoul, Republic of Korea

${ }^{2}$ Department of Occupational and Environmental Medicine, Hallym University Sacred Heart Hospital, Republic of Korea ${ }^{3}$ Korea Occupational Safety and Health Agency, Ulsan, Republic of Korea ${ }^{4}$ Occupational Safety and Health Research Institute, Korea Occupational Safety and Health Agency, Ulsan, Republic of Korea

\section{Correspondence to} Dr Eun-A Kim, Occupational Safety and Health Research Institute, 400, Jongga-ro, Jung-gu, Ulsan 681-230, South Korea;

toxneuro@gmail.com

Received 17 July 2015 Revised 21 January 2016 Accepted 1 February 2016 Published Online First 26 February 2016

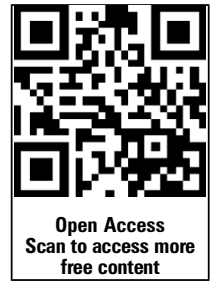

\section{ABSTRACT}

Objective The present study sought to identify inequalities in cause-specific mortality across different occupational groups in Korea.

Methods The cohort included Korean workers enrolled in the national employment insurance programme between 1995 and 2000. Mortality was determined by matching death between 1995 and 2008 according to a nationwide registry of the Korea National Statistical Office. The cohort was divided into nine occupational groups according to the Korean Standard Occupational Classification (KSOC). Age-standardised mortality rates of each subcohort were calculated.

Results The highest age-standardised mortality rate was identified in KSOC 6 (agricultural, forestry and fishery workers; male (M): 563.0 per 100 000, female (F): 206.0 per 100 000), followed by KSOC 9 (elementary occupations; M: 499.0, F: 163.4) and KSOC 8 (plant, machine operators and assemblers; M: 380.3, $\mathrm{F:}$ 157.8). The lowest rate occurred in KSOC 2 (professionals and related workers; M: 209.1, F: 93.3). Differences in mortality rates between KSOC 2 and $\mathrm{KSOC}$ 9 (M: 289.9, F: 70.1) and the rate ratio of KSCO9 to KSCO2 (M: 2.39, F: 1.75) were higher in men. The most prominent mortality rate difference was observed in external causes of death (M: 96.9, F: 21.6) and liver disease in men (38.3 per 100 000). Mental disease showed the highest rate ratio (M: 6.31, F: 13.00). Conclusions Substantial differences in mortality rates by occupation were identified. Main causes of death were injury, suicide and male liver disease. Development of policies to support occupations linked with a lower socioeconomic position should be prioritised.

\section{INTRODUCTION}

Since the Black Report was published by the Working Group on Inequalities in Health in 1980, social inequalities in mortality have been an important public health issue in many countries. ${ }^{1}$ Korea has undergone very rapid industrialisation, and was recently classified as an industrialised country by the World Bank; in 1960, it was still considered an agricultural country. With industrialisation, the Gini index, which measures socioeconomic inequality, decreased gradually up until the mid-1990s, but this trend reversed with the financial crisis in the mid-1990s and the subsequent economic, social and political changes. Numerous studies have investigated the relationship between socioeconomic position (SEP) and mortality in Korea. $^{2-7}$ In these studies, the variables used to

\section{What this paper adds}

- Numerous studies have investigated the relationship between socioeconomic position and mortality in Korea, but there have been few detailed reports of differences between occupation groups because most studies categorise occupations simply into manual and non-manual labour.

- This study evaluated differences in cause-specific mortalities in nine different occupational groups by following a large nationwide cohort of Korean employees.

- Substantial differences in mortality rates by occupation were identified. Injury, suicide and male liver disease were important contributors to mortality inequality between occupation groups.

classify SEP were education, income and occupation. However, studies that used occupation as the SEP were limited by the high likelihood of misclassifying individuals, as occupational information is recorded on the death certificate by relatives of the deceased. ${ }^{6} 7$ In studies that relied on death certificates, the mortality rate according to SEP was estimated by unlinked data, deriving the nominator from national death data and the denominator from national census data rather than by following study participants. ${ }^{2}$ 5-7 Additionally, there have been few detailed reports of differences between occupation and/or industry groups, given that most studies divide occupation simply as those who participate in manual labour and those who do not. ${ }^{4}$

The aim of this study was to evaluate differences in cause-specific mortality between different occupational groups by following a large nationwide data set of Korean employees. We have previously reported a portion of our results in the form of an abstract. $^{8}$

\section{MATERIALS AND METHODS \\ Data source}

Since 1995, the Employment Insurance Act has required currently employed workers to join the employment insurance programme in Korea. Information on workers who have joined the employment insurance programme between 1995 and 2000 was obtained from the Korea 
Employment Information Service under the Ministry of Labor. Information on each worker included the identification number, sex, date of birth, date of joining and leaving the insurance programme, occupational group classified by the Korean Standard Classification of Occupations (KSCO) and the industry of the company as classified by the Korean Standard Industrial Classification. Data were collected for 11435937 workers.

\section{Cohort identification}

The cohort included Korean employees enrolled in employment insurance between 1995 and 2000; we only included workers who were aged $>15$ and $<60$ years when they enrolled. Subcohorts by occupation group included only workers who engaged in a single occupation throughout the whole period covered by employment insurance from 1995 to 2000. Consequently, a worker who changed occupational classification or a worker without information of occupational classification was excluded from the cohort.

Occupational groups were classified into nine categories according to KSCO (KSCO1=legislators, senior officials and managers; $\mathrm{KSCO} 2=$ professionals; $\mathrm{KSCO} 3=$ technicians and associate professionals; $\mathrm{KSCO} 4=$ clerks; $\mathrm{KSCO} 5=$ service workers and sale workers; KSCO6=agricultural, forestry and fishery workers; KSCO7=craft and related trades workers; KSCO $8=$ plant and machine operators and assemblers; and KSCO9=elementary occupations). Elementary occupations consist of simple and routine tasks (eg, street cleaning, carrying luggage, door keeping, and monitoring and packing manufactured products by hand).

\section{Mortality follow-up and mortality rate calculation}

The cohort data set was sent to the Korea National Statistical Office (KNSO) for matching deaths between 1995 and 2008. KNSO provided information on the matched cases for the cause of death according to the International Classification of Diseases-10 and the date of death. Population data were also obtained from KNSO using the resident registration population on 1 July of each year. ${ }^{9}$ Age-standardised rates (ASRs) were determined by direct standardised methods using data from the resident population registry in the year 2000 as the standard population. To compare the mortality between occupational groups, we calculated rate ratios and rate differences between specific occupational groups. Rate ratios were calculated by dividing ASRs of KSCO9 by ASRs of KSCO2. Rate differences were the differences between ASRs of KSCO9 and ASRs of KNSO2.

\section{Ethics statement}

The institutional review boards of the Occupational Safety and Health Research Institute and Korea Occupational Safety and Health Agency, Incheon, Korea approved this study.

\section{RESULTS}

In total, 8762340 workers were eligible for analysis (table 1). Males comprised $63.3 \%$ of the study group. The most common occupational groups were crafts and related trades workers, to which $25.4 \%$ of males belonged, and clerks, to which $37.2 \%$ of females belonged. Agricultural, forestry and fishery workers accounted for a very small portion of the study population $(0.3 \%)$.

By the end of the mortality follow-up period, 231239 $(2.6 \%)$ workers had died; the observed study participants represented 99414095 person-years in total. The overall mean length of follow-up was 11.3 years.

ASRs by sex and occupation are shown in tables 2 and 3. The ASR for all-cause mortality was 342.6 per 100000 among males and 141.6 per 100000 among females in the total cohort (data not shown). Agricultural, forestry and fishery workers showed the highest ASR for mortality (male (M): 563.0, female (F): 206.0), followed by elementary occupations (M: 499.0, F: 163.4), and plant and machine operators and assemblers (M: 380.3, F: 157.8). The lowest ASR was observed in professionals (M: 209.1, F: 93.3). The highest ASR for mortality due to neoplasms (C00-D48) was shown in elementary occupations (M: 146.4, F: 163.4). The lowest ASR due to neoplasms was shown in professionals (M: 93.2, F: 46.9) and managers (M: 92.1, F: 41.0). The highest ASR for external causes of death (V01-Y89) was seen in agricultural, forestry and fishery workers (M: 235.1, F: 74.7); the lowest was observed in professionals (M: 36.2, F: 15.1).

Differences in mortality rates between professionals and elementary occupations (absolute inequality) and the mortality rate ratio of professionals to elementary occupations (relative inequality) are also shown in tables 2 and 3. Those in professional occupations had the lowest all-cause mortality rates, whereas those in the elementary occupations had the second highest rates. Agricultural, forestry and fishery workers showed the highest mortality, but the total number of observed deaths were minimal due to this category having the fewest overall person-years. For this reason, we presented the absolute difference in mortality rate and mortality rate ratio between professionals and elementary occupations. Differences in all-cause mortality were higher in men than in women with rate

Table 1 Number of participants, person-years and number of deaths by occupation and sex

\begin{tabular}{|c|c|c|c|c|c|c|}
\hline \multirow[b]{2}{*}{ KSCO } & \multicolumn{3}{|l|}{ Male } & \multicolumn{3}{|l|}{ Female } \\
\hline & $\mathrm{N}(\%)$ & Person-years & Deaths & $\mathrm{N}(\%)$ & Person-years & Deaths \\
\hline 1. Legislators, Senior Officials and Managers & $309942(5.7)$ & 3812848 & 11726 & $25397(0.8)$ & 287634 & 265 \\
\hline 2. Professionals & $208496(3.8)$ & 2433328 & 3602 & $134769(4.1)$ & 1460715 & 679 \\
\hline 3. Technicians and Associate Professionals & $558992(10.2)$ & 6300791 & 13527 & $181612(5.5)$ & 1940756 & 1140 \\
\hline 4. Clerks & $1312591(23.9)$ & 15522591 & 25522 & $1220276(37.2)$ & 13698877 & 5556 \\
\hline 5. Service and Sale Workers & $498669(9.1)$ & 5550875 & 13467 & $462915(14.1)$ & 5034638 & 3905 \\
\hline 6. Agricultural, Forestry and Fishery Workers & $20805(0.4)$ & 236380 & 1515 & $2424(0.1)$ & 25917 & 53 \\
\hline 7. Craft and Related Trades Workers & $1390143(25.4)$ & 16113423 & 50588 & $508701(15.5)$ & 5888152 & 6727 \\
\hline 8. Plant and Machine Operators and Assemblers & $396428(7.2)$ & 4699779 & 17904 & $87942(2.7)$ & 1007602 & 998 \\
\hline 9. Elementary Occupations & 786901 (14.4) & 8243587 & 60316 & $655337(20.0)$ & 7156203 & 13749 \\
\hline Total & $5482967(100.0)$ & 62913602 & 198168 & $3279373(100.0)$ & 36500494 & 33074 \\
\hline
\end{tabular}

KSCO, Korean Standard Classification of Occupations. 
Table 2 Age-standardised cause-specific mortality rate by occupation, rate ratio and rate difference between KSC09 and KSCO2 (males, per $100000)$

\begin{tabular}{|c|c|c|c|c|c|c|c|c|c|c|c|}
\hline Occupation group & KSC01 & $\mathrm{KSCO} 2$ & KSCO3 & KSCO4 & KSCO5 & KSCO6 & KSCO7 & KSC08 & KSCO9 & $\mathbf{R R}$ & RD \\
\hline \multicolumn{12}{|l|}{ Cause of death } \\
\hline All causes & 252.8 & $209.1^{*}$ & 285.6 & 249.7 & 362.0 & $563.0 \dagger$ & 365.1 & 380.3 & 499.0 & 2.39 & 289.9 \\
\hline Certain infectious and parasitic diseases (A00-B99) & $3.6^{*}$ & 5.5 & 6.1 & 5.3 & 8.1 & 10.5 & 7.1 & 8.5 & $12.6 \dagger$ & 2.29 & 7.1 \\
\hline Neoplasms (C00-D48) & $92.1^{*}$ & 93.2 & 107.7 & 103.2 & 123.4 & 117.3 & 120.8 & 117.2 & $146.4 \dagger$ & 1.57 & 53.2 \\
\hline Malignant neoplasm of the stomach (C16) & 14.8 & $13.8^{*}$ & 16.4 & 15.0 & 18.7 & 19.8 & 21.4 & 20.5 & $26.4 \dagger$ & 1.91 & 12.6 \\
\hline $\begin{array}{l}\text { Malignant neoplasm of the colon, rectosigmoid junction, } \\
\text { rectum, anus and anal canal (C18-C21) }\end{array}$ & $8.1^{*}$ & $11.0+$ & 9.3 & 10.1 & 10.7 & 10.0 & 8.5 & 8.6 & 10.8 & 0.98 & -0.2 \\
\hline $\begin{array}{l}\text { Malignant neoplasm of the liver and intrahepatic bile } \\
\text { ducts (C22) }\end{array}$ & 23.2 & $21.8^{*}$ & 25.6 & 24.6 & 30.3 & 31.6 & 29.2 & 28.7 & $34.5 t$ & 1.58 & 12.7 \\
\hline $\begin{array}{l}\text { Malignant neoplasm of the trachea, bronchus and lung } \\
\text { (C33-C34) }\end{array}$ & 15.6 & $15.2^{*}$ & 23.6 & 21.0 & 26.0 & 22.3 & 26.7 & 25.5 & $32.4 \dagger$ & 2.13 & 17.2 \\
\hline Malignant neoplasm of the bladder (C67) & 1.1 & 0.8 & $1.8 \dagger$ & 1.5 & 1.1 & $0.3^{*}$ & 1.0 & 1.1 & 1.2 & 1.50 & 0.4 \\
\hline Non-Hodgkin's lymphoma (C82-C85) & 1.9 & $3.6+$ & 2.3 & 2.3 & 2.4 & $1.7^{*}$ & 2.4 & 2.5 & 2.6 & 0.72 & -1.0 \\
\hline Leukaemia (C91-C95) & 3.3 & $2.3^{*}$ & 2.4 & 2.4 & $3.7 \dagger$ & 3.0 & 2.8 & 3.2 & 3.0 & 1.30 & 0.7 \\
\hline Mental and behavioural disorders (F00-F99) & $0.7^{*}$ & 1.3 & 2.2 & 1.5 & 3.7 & $8.9+$ & 4.0 & 3.6 & 8.2 & 6.31 & 6.9 \\
\hline Diseases of the nervous system (G00-G99) & 2.5 & $1.7^{\star}$ & 2.7 & 3.1 & 3.7 & 2.0 & 3.4 & 3.4 & $4.9+$ & 2.88 & 3.2 \\
\hline Diseases of the circulatory system (100-199) & $36.5^{*}$ & 39.3 & 43.5 & 41.9 & 64.4 & $87.9+$ & 56.2 & 67.8 & 80.0 & 2.04 & 40.7 \\
\hline Ischaemic heart diseases (120-125) & $11.6^{*}$ & 14.7 & 14.6 & 13.2 & 19.0 & $25.8 \dagger$ & 17.4 & 23.9 & 21.0 & 1.43 & 6.3 \\
\hline Cerebrovascular diseases (160-169) & 15.9 & $14.8^{*}$ & 19.6 & 19.5 & 31.9 & $42.9 \dagger$ & 26.2 & 28.5 & 40.9 & 2.76 & 26.1 \\
\hline Diseases of the respiratory system ( $\mathrm{J00-J99)}$ & $4.5^{*}$ & 5.2 & 6.1 & 6.3 & 12.8 & 14.8 & 10.7 & 9.9 & $15.1 \dagger$ & 2.90 & 9.9 \\
\hline Pneumonia (J12-J18) & $1.1^{*}$ & 2.0 & 1.2 & 1.4 & 2.5 & $4.9+$ & 2.3 & 2.3 & 3.9 & 1.95 & 1.9 \\
\hline Chronic lower respiratory diseases (J40-J47) & $1.5^{*}$ & 1.7 & 2.5 & 2.6 & $6.3+$ & 6.1 & 3.8 & 4.0 & 6.1 & 3.59 & 4.4 \\
\hline Diseases of the digestive system (K00-K93) & $9.2^{*}$ & 10.8 & 17.3 & 12.9 & 23.2 & 40.4 & 25.4 & 19.5 & $52.2+$ & 4.83 & 41.4 \\
\hline Diseases of the liver (K70-K77) & $7.7^{*}$ & 8.3 & 15.3 & 10.6 & 19.8 & 32.6 & 22.5 & 16.4 & $46.6+$ & 5.61 & 38.3 \\
\hline $\begin{array}{l}\text { Diseases of the musculoskeletal system and connective } \\
\text { tissue (M00-M99) }\end{array}$ & 0.5 & $0.2^{*}$ & 0.3 & 1.0 & 0.7 & $3.3+$ & 0.8 & 0.9 & 1.1 & 5.50 & 0.9 \\
\hline Diseases of the genitourinary system (N00-N99) & 2.5 & $1.6^{*}$ & 3.2 & 3.7 & 4.3 & $7.0 \dagger$ & 3.0 & 4.0 & 4.3 & 2.69 & 2.7 \\
\hline External causes of morbidity and mortality (V01-Y98) & 86.2 & $36.2^{*}$ & 78.1 & 54.5 & 86.2 & $235.1+$ & 108.7 & 117.4 & 133.1 & 3.68 & 96.9 \\
\hline Transport crashes (V01-V99) & 55.9 & $12.7^{*}$ & 31.6 & 23.0 & 34.5 & $87.5+$ & 43.6 & 43.8 & 49.2 & 3.87 & 36.5 \\
\hline Intentional self-harm (X60-X84) & 14.0 & $11.7^{*}$ & 22.6 & 16.9 & 30.0 & $54.3 \dagger$ & 31.6 & 43.8 & 44.2 & 3.78 & 32.5 \\
\hline
\end{tabular}

differences (M: 289.9 per $100000, \mathrm{~F}: 70.1$ per 100000$)$ and with rate ratios of $\mathrm{M}: 2.39$ and $F: 1.75$. In male workers, the most noteworthy causes of deaths were mental diseases (rate ratio of 6.31), liver diseases (5.61), diseases of the musculoskeletal system (5.50), vehicular crushing accidents (3.87) and suicide (3.78) in the relative aspect. In female workers, the rate ratios of mental disease (13.00), disease of the musculoskeletal system (13.00) and ischaemic heart disease (IHD) (5.17) were higher. The most prominent mortality rate difference was observed for external causes of death (M: 96.9, F: 21.6 per 100 000). Among men, the difference was also pronounced for diseases of the liver (38.3 per 100 000).

\section{DISCUSSION}

The most prominent finding in our study was that there were substantial differences in mortality rates among different occupation categories, which reflect the overall SEP. In addition to SEP, different occupations have varying levels of exposure to hazards. Overall mortality was much higher in lower occupational categories such as elementary occupations or agricultural, forestry and fishery industries than in higher occupational categories such as legislators, senior officials and managers and professionals in both sexes. Occupation is a good discriminator of socioeconomic inequalities in health, including mortality. ${ }^{10-12}$
According to a 'Survey on Labor Conditions by Employment Type' performed by the Korean Ministry of Employment and Labor in 2013, the monthly wage was highest among legislators, senior officials and managers (approximately \$5000), followed by professionals and related workers (approximately \$3000). Occupations with the lowest incomes were elementary occupations (approximately \$1400) and service and sale workers (approximately \$1700). ${ }^{13}$ Aside from income, occupation can also reflect overall educational level, exposure to hazards and social standing. ${ }^{11}$

Inequalities in mortality among different occupational categories varied according to gender. The all-cause mortality rate difference between professionals and elementary occupations was much higher in men $(289.9$ per 100000$)$ than in women (70.1 per 100000$)$. This might be due to the difference in overall mortality rates between men and women, which are 209.1-563.0 per 100000 and 93.3-206.0 per 100000 , respectively. However, the rate ratio of elementary workers to professionals was also higher in men (2.39) than in women (1.75). Previous studies of populations in the USA that used education as an SEP indicator also reported that socioeconomic mortality differences were greater among men than in women, although marital status played a role as a confounder. ${ }^{14} 15$ Data from Western countries cannot be directly applied to Korean 
Table 3 Age-standardised cause-specific mortality rate by occupation, rate ratio and rate difference between KSC09 and KSC02 (females, per $100000)$

\begin{tabular}{|c|c|c|c|c|c|c|c|c|c|c|c|}
\hline Occupation group & KSC01 & KSCO2 & KSCO3 & KSCO4 & KSCO5 & KSCO6 & KSCO7 & KSCO8 & KSCO9 & $\mathbf{R R}$ & RD \\
\hline \multicolumn{12}{|l|}{ Cause of death } \\
\hline All causes & 122.3 & $93.3^{*}$ & 136.4 & 115.7 & 149.7 & $206.0 \dagger$ & 158.1 & 157.8 & 163.4 & 1.75 & 70.1 \\
\hline Certain infectious and parasitic diseases (A00-B99) & 1.1 & 3.1 & 2.1 & 2.2 & 3.2 & $0.0^{*}$ & 3.8 & $6.8 \dagger$ & 3.7 & 1.19 & 0.6 \\
\hline Neoplasms (C00-D48) & $41.0^{*}$ & 46.9 & 64.1 & 63.0 & 62.3 & 57.1 & 62.8 & $65.4 \dagger$ & 63.1 & 1.35 & 16.2 \\
\hline Malignant neoplasm of the stomach (C16) & $5.5^{*}$ & 5.7 & 13.1 & 7.5 & 9.7 & $13.9+$ & 10.0 & 9.7 & 10.4 & 1.82 & 4.7 \\
\hline $\begin{array}{l}\text { Malignant neoplasm of the colon, rectosigmoid junction, } \\
\text { rectum, anus and anal canal (C18-C21) }\end{array}$ & $4.4^{*}$ & 5.2 & 4.5 & 7.9 & 6.6 & $11.0 t$ & 7.2 & 5.6 & 6.5 & 1.25 & 1.3 \\
\hline $\begin{array}{l}\text { Malignant neoplasm of the liver and intrahepatic bile } \\
\text { ducts (C22) }\end{array}$ & 4.8 & 5.7 & 5.3 & $4.5^{*}$ & 7.1 & 8.5 & 7.1 & $12.6+$ & 7.2 & 1.26 & 1.5 \\
\hline $\begin{array}{l}\text { Malignant neoplasm of the trachea, bronchus and lung } \\
\text { (C33-C34) }\end{array}$ & $6.1^{*}$ & 8.3 & $10.6+$ & 8.7 & 7.4 & 7.2 & 8.5 & 6.2 & 8.2 & 0.99 & -0.1 \\
\hline Malignant neoplasm of the bladder (C67) & 0.2 & $0.0^{*}$ & $0.0^{*}$ & $0.4 \dagger$ & 0.3 & $0.0^{*}$ & 0.1 & $0.0^{*}$ & 0.2 & - & 0.2 \\
\hline Non-Hodgkin's lymphoma (C82-C85) & 0.6 & 0.4 & 0.5 & 1.0 & 1.1 & $0.0^{*}$ & 1.0 & $1.8 \dagger$ & 1.4 & 3.50 & 1.0 \\
\hline Leukaemia (C91-C95) & 1.2 & $2.8 \dagger$ & 1.9 & 1.1 & 1.7 & $0.0^{*}$ & 2.3 & $2.8 \dagger$ & 2.0 & 0.71 & -0.8 \\
\hline Mental and behavioural disorders (F00-F99) & $0.0^{*}$ & 0.1 & 0.2 & 0.3 & $1.5+$ & $0.0^{*}$ & 0.9 & 0.2 & 1.3 & 13.00 & 1.2 \\
\hline Diseases of the nervous system (G00-G99) & 0.5 & 2.2 & 1.0 & $3.6+$ & 1.6 & $0.0^{*}$ & 2.5 & 1.5 & 3.0 & 1.36 & 0.8 \\
\hline Diseases of the circulatory system (100-199) & 20.0 & $9.7^{*}$ & 19.4 & 17.3 & 21.8 & 22.6 & 29.9 & 26.1 & $30.9 \dagger$ & 3.19 & 21.2 \\
\hline Ischaemic heart diseases (120-125) & 3.3 & $1.2^{*}$ & 2.1 & 4.7 & 4.7 & $7.1 \dagger$ & 6.7 & 6.4 & 6.2 & 5.17 & 5.0 \\
\hline Cerebrovascular diseases (160-169) & 13.1 & $7.7^{*}$ & 9.2 & 10.5 & 13.1 & 13.1 & 17.0 & 13.1 & $17.3+$ & 2.25 & 9.6 \\
\hline Diseases of the respiratory system (J00-J99) & 12.5 & 5.8 & 5.9 & $1.8^{*}$ & 5.0 & $32.0+$ & 5.1 & 3.1 & 3.3 & 0.57 & -2.5 \\
\hline Pneumonia (J12-J18) & $5.5 t$ & 2.0 & 0.4 & 0.7 & 0.3 & $0.0^{*}$ & 1.5 & 0.7 & 0.9 & 0.45 & -1.1 \\
\hline Chronic lower respiratory diseases (J40-J47) & $5.5 \dagger$ & 1.7 & 5.1 & 0.5 & 2.4 & $0.0^{*}$ & 2.3 & 1.8 & 1.6 & 0.94 & -0.1 \\
\hline Diseases of the digestive system (K00-K93) & 2.5 & $1.8^{*}$ & 3.0 & 2.2 & 3.5 & 4.4 & 5.3 & $7.2 \dagger$ & 4.7 & 2.61 & 2.9 \\
\hline Diseases of the liver (K70-K77) & $1.6^{*}$ & 1.7 & 2.7 & $1.6^{*}$ & 2.5 & 4.4 & $4.6 \dagger$ & 3.0 & 3.5 & 2.06 & 1.8 \\
\hline $\begin{array}{l}\text { Diseases of the musculoskeletal system and connective } \\
\text { tissue (M00-M99) }\end{array}$ & 0.3 & 0.1 & 0.6 & 0.4 & $1.4 \dagger$ & $0.0^{*}$ & 1.1 & 0.7 & 1.3 & 13.00 & 1.2 \\
\hline Diseases of the genitourinary system (N00-N99) & 0.2 & 0.8 & 0.6 & 1.2 & 2.6 & $0.0^{*}$ & $3.4 \dagger$ & 1.6 & 2.5 & 3.13 & 1.7 \\
\hline External causes of morbidity and mortality (V01-Y98) & 40.2 & $15.1^{*}$ & 20.8 & 18.5 & 33.5 & $74.7 \dagger$ & 33.9 & 34.6 & 36.7 & 2.43 & 21.6 \\
\hline Transport crashes (V01-V99) & 9.5 & $5.0^{*}$ & 7.0 & 8.6 & 10.0 & $45.0 \dagger$ & 11.0 & 11.3 & 13.4 & 2.68 & 8.4 \\
\hline Intentional self-harm (X60-X84) & $22.8+$ & 7.5 & 7.9 & $6.8^{*}$ & 14.9 & 14.6 & 14.5 & 12.3 & 14.7 & 1.96 & 7.2 \\
\hline
\end{tabular}

adults because the social structures pertaining to gender, socioeconomic inequalities and causes of death in Korea differ substantially from those in Western countries. In previous studies in Korea, SEP and all-cause mortality associations were higher among men than in women, although the differences were not statistically tested. ${ }^{3} 7$ In this study, mortality differences between occupations caused by neoplasms, circulatory disease, mental disorder and external causes were noted in male and female workers. In the cases of lung cancer and chronic lower respiratory diseases, which were important causes of death with varying rates depending on occupational categories in men, there were no differences in rates between occupational groups for women. The rate ratio of liver diseases was much higher in men than in women. These findings suggest that health behaviour, including smoking and alcohol consumption, may explain gender differences in mortality disparity. ${ }^{14} 15$

It is important to understand the pattern of the contribution of specific cause of death to decrease socioeconomic inequalities in mortality. ${ }^{216} 17$ In this study, the main sources of mortality differences were external causes of mortality, including transport crashes and suicide, and liver and cerebrovascular diseases. In the previous study, which used education as an SEP indicator, the contribution of the cause of death to inequality in mortality in Korea demonstrated a similar pattern. ${ }^{2}$ In studies in Sweden,
Finland, Norway and the UK, the most important source of mortality variation among different SEP groups was cardiovascular disease; which was responsible for $\geq 30 \%$ of mortality inequality. ${ }^{17} 18$ In this study, the role of IHD was not as high in male workers, although mortality inequality for IHD was higher in female workers. In female workers, the 'professionals' occupation group, which was used as the reference group, had a much lower IHD-caused mortality rate compared to other occupation groups. As a result, the rate ratio of IHD was high. This might be due to differences in the distribution of important IHD risk factors (eg, cholesterol and obesity) among occupation groups. ${ }^{19}$

Compared to Western countries, one of the most prominent differences in mortality was the contribution of external causes. In our study, an external cause accounted for $33.4 \%$ and $30.8 \%$ of mortality differences between professionals and elementary occupations in male and female workers, respectively. These differences are much higher than in previous reports from Sweden and the Netherlands, where mortality inequalities due to external causes were only $2-5 \% .{ }^{17}{ }^{20}$ In terms of relative inequality, external causes were a noteworthy cause of death in men and women, with rate ratios of 3.68 and 2.43 , respectively.

Occupational injury can be a significant cause of inequality in external causes of mortality because of falls and/or exposure to 
heavy mechanical equipment. There were 1090 compensated mortality cases caused by occupational injury (approximately 7.1 per 100000 workers) in $2013 .^{21}$ Mortality from workrelated injuries in Korea is much higher than in Western countries. In the USA, for example, the mortality rate from workrelated injuries was 3.7 per 100000 workers during 2005$2009 .^{22}$ Inequality in mortality from other external causes of accidental injury is presumed to be mainly related to differences in exposure to occupational hazards.

Approximately one-third of differences in mortality due to external causes were caused by transport vehicle accidents. The mortality rate due to such accidents was particularly high among both sexes in agricultural, forestry and fishery workers. This suggests that mortality inequality might be affected by work-related transport crashes. Generally, the association between SEP and mortality from such accidents may be explained by accessibility to a new vehicle or to protective gear, the risk of pedestrian injury because of the living environment, and behavioural factors (including alcohol consumption or use of a seat belt). ${ }^{23}$ In some European studies, women seldom showed inequality in mortality from traffic crashes. ${ }^{20} 23$ Similarly, a previous study in Korea showed that inequality in mortality due to transport crashes was less in women than in men. ${ }^{2}$ Although absolute mortality rate differences in this study were much smaller in females than in males, the magnitude of relative inequality and the contribution of transport crashes to mortality inequality were not widely different between men and women. Considering that the participants of this study were employed workers, the possibilities of exposure to traffic may be higher among working females than in the general female population.

Another one-third of mortality rate differences by external causes was comprised of intentional self-harm, that is, suicide, the mortality rate ratio for which was also high. Socioeconomic factors, including lower education and lower income, as well as employment status, are well-known risk factors for suicide. ${ }^{24-26}$ Among men, the highest suicide mortality rates were observed among agricultural, forestry and fishery workers; the mortality rate was five times that of professionals. Farmers are at a higher risk of suicide compared to the general population. ${ }^{27}$ Moreover, agricultural workers in Korea have significantly elevated mortality due to suicide compared to the general population, and suicide by pesticide ingestion is prevalent in rural areas. ${ }^{28}$ Thus, in addition to socioeconomic strain, easy access to pesticides may play a role in increasing suicide-based mortality. ${ }^{29}$ In the case of women, although individuals engaged in lower SEP occupations showed higher mortality due to suicide than professionals, the highest mortality rate was unexpectedly observed in legislators, senior officials and managers. The derived mortality rate was based on a small denominator because the proportion of female legislators, senior officials and managers was very small. To obtain a more reliable and representative result, a longer follow-up period is required.

The finding that external causes of mortality contributed substantially to mortality inequality among occupation categories has important implications. Substantial efforts must be made to prevent accidents and suicide in all of society. In a study in Norway, which is one of the countries with the lowest income inequalities, it was reported that mortality inequality from an external cause among different education groups decreased significantly from 1960 to $2000 .^{20}$ External cause of mortality is likely to be one of the most sensitive causes of mortality inequality affected by improvements in social policy and culture.

Liver disease contributed to a substantial proportion of mortality inequality among men, where liver disease and liver cancer accounted for $17.6 \%$ of the mortality rate difference between professionals and elementary occupations. In case of women, the rate ratio of elementary occupations to professionals was 2.06, although the mortality rate difference was small (1.8 per 100000$)$. This finding is consistent with a previous study. ${ }^{2}$ Inequality of mortality attributable to alcohol, including liver disease, widened during the economic crisis. ${ }^{6}$ In the case of liver disease, SEP-related behavioural factors, with alcohol consumption in particular, was presumed to play a major role in mortality inequality. Additionally, it was reported that lower income and lower education groups received hepatitis $\mathrm{B}$ vaccinations less frequently. ${ }^{30}$ Moreover, the hepatitis A infection rate was higher among lower income and education groups. ${ }^{31}$ Inequalities in hepatitis infection may also affect the inequality in mortality due to liver disease and liver cancer. Besides, liver disease is an important occupational disease for workers exposed to various solvents or to the hepatitis virus.

Cancer was also a source of mortality inequality. Stomach cancer showed great inequality in both sexes. Lung cancer inequality was observed only in men. Two factors that contribute to cancer mortality inequality include overall incidence and survival. The incidence of smoking or alcohol-related cancers, for example, may be affected by health behaviours that are tightly associated with SEP. Moreover, occupational or environmental exposure to carcinogens is expected to play a role in inequality of cancer-related mortalities among the different occupational categories. Lung cancer inequality in men is expected to be partly related to occupational exposure, as lung cancer is the most common occupational cancer. However, lymphoid, haematopoietic and bladder cancers, which are candidates for occupational cancers, showed no noteworthy inequalities among the occupational groups. ${ }^{32}$ This may be due to a very small portion of carcinogen-exposed workers among the entire study population. The main suggested mechanism underlying inequalities in cancer survival is disparity in the access to healthcare, leading to differences in disease stage at diagnosis as well as treatment modality. ${ }^{33}$ Differences in participation in opportunistic cancer screening programmes according to educational level were observed in Korea. ${ }^{34}$ Although there is a national healthcare insurance system covering the entire Korean population, additional efforts should be made to achieve equal access to basic preventive healthcare services.

Mental disease showed a noteworthy mortality rate ratio of elementary occupations to professionals (M: 6.31, F: 13.00), although the mortality rate difference was not noticeable. The relationship between SEP and mental disease mortality can be explained in two ways. First, the lower SEP group is associated with a higher incidence of mental disease because of more risk factors (eg, high stress and weaker social support). ${ }^{35}$ Second, the inequality can be exacerbated by differential access to treatment. $^{36}$

In this study, the results are presented mainly as descriptive statistics. In some previous studies, the 'relative index of inequality' was used to show gradients in mortality. ${ }^{2}{ }^{3}$ However, we could not apply this method because job categories cannot be classified in order. Cox proportional hazard models are another method to test the null hypothesis that mortality among various occupational groups is equal. However, we focused on presenting cause-specific mortality data for each occupational category using a large cohort. Although most groups had sufficient populations to show descriptive results, agricultural, forestry and fishery workers, as well as female legislators, senior officials and managers, represented a very small proportion of the participants $(<1.0 \%)$. We used direct standardisation to compare 
mortality between different populations. Considering that direct standardisation is sensitive to small population size, the results for these groups might be far less reliable than those for other occupations. For the same reason, we did not use the results of these groups for calculating the ratio or difference of mortality rates.

To calculate mortality rates, we did not apply the latent period. Instead, we used person-years and death data from inclusion of the cohort. Following a cohort without a latent period could produce the problem of reverse causation. Despite this, we considered that most of the participants had been employed workers since before 1995 (the start of employment insurance) or before entering the insurance programme. In cases of chronic disease, however, the probability of reverse causation still exists to some degree.

We constructed cohorts with workers who had single occupations during 1995-2000. However, since the participants were working when the employment insurance programme began, we could not exclude workers who changed their occupations before 1995. If a person changed their occupation to a lower SEP-related job because of illness before 1995, there is also a risk of reverse causation.

The greatest strength of this study was the cohort size and the extent to which it reflects the working population of Korea. We followed 8762340 employed workers for approximately 13 years. Our data encompassed $28.6 \%$ of the Korean population between the ages of 20 and 64 years in $2000 .{ }^{9}$

Participants were members of the employment insurance programme operated by the government during 1995-2000. In 1995 , when insurance was introduced for the first time, employees in a company with $>30$ workers in the private sector were eligible for membership. ${ }^{8}$ Although insurance covered only $33.2 \%$ of total employed workers at the time, coverage increased in stages to include workers in companies with $\geq 1$ employee; the rate of coverage approached $65 \%$ by $2000 .{ }^{37}$ The majority of the employed workers included in our study were employees of the private sector, and non-regular workers (ie, part-time workers) were not included. For this reason, the scope of this study is confined to regular, full-time workers in the private sector of Korea. The representation can vary across occupational groups. For example, agricultural, forestry and fishery workers included in this study were employed workers; however, most of the agricultural and fishery workers in Korea are self-employed. Hence, the study participants in this category (KSCO6) do not represent the entire working population; participants from other occupational categories are presumed to represent a much larger proportion of their respective groups.

Another strength of this study was that we documented the cause-specific mortality rates among nine occupational categories. Accordingly, the mortality gradient among various occupational groups was determined. Participants have been classified into manual and non-manual labourers in previous studies of mortality inequality between occupational classes in Korea. ${ }^{4} 67$ The reason for this approach is presumed to be the lack of a sufficient number of study participants for additional stratification plus the risk of misclassifying occupations by relying on death certificate information. ${ }^{7}$ In this study, occupational information was obtained from employment insurance data, which were provided by the employees' respective companies; hence, the reliability of our information is expected to be markedly higher. Moreover, a sufficient number of deaths from a very large longitudinal data set enabled us to create nine occupation subcohorts.

The mortality rates in this study were calculated by following a longitudinal cohort. Several previous studies on mortality inequality in Korea were limited by using unlinked data for the numerator and denominator. ${ }^{5-7} 26$ In studies using linked data, the numbers of participants were insufficient to evaluate causespecific mortality or else participants were limited to a specific population. $^{3}{ }^{4}$

There were also some limitations in our study. We assumed that all unmatched workers in the KNSO death registry, which covers the entire country, were alive. However, if some workers had emigrated from Korea before 2008 and had died during the study period, the mortality rate of the cohort would be artificially lowered. Moreover, if such deaths abroad had occurred disproportionately by occupational group, the results could be skewed. However, the emigration rate in Korea was very low $(<0.04 \% \text { per year between } 2002 \text { and } 2008)^{38}$; therefore, any bias in the results was unlikely to be appreciable.

We calculated cause-specific mortality rates based on death certificate information, and there have been disputes regarding the accuracy of the stated causes of death on these certificates. ${ }^{39}$ In the previous Korean study, the accuracy of the stated cause of death on death certificates was $91.9 \%$ when compared to the medical records of the deceased in one university hospital in Seoul, ${ }^{40}$ and the accuracy is expected to be much lower when including certificates issued in small hospitals and rural areas. Considering the inequality of access to healthcare service, it is possible that the accuracy of death certificates can also depend on SEP. To minimise this problem, we used the cause of death code chapter level or group of the 3-digit codes.

\section{CONCLUSIONS}

A profound inequality in mortality rates among occupational groups in Korea was observed. The leading causes of death contributing to mortality inequality across occupational groups were external causes of mortality in both sexes and liver disease in men. To reduce mortality inequality, injury and suicide prevention targeting elementary occupations and agricultural workers should be prioritised. Moreover, the prevention of liver disease in male elementary workers should be addressed when developing policies aimed at remediating health inequalities.

\section{Twitter Follow EUN-A KIM at @euna0}

Contributors $\mathrm{H}$-EL and E-AK designed the study and performed the analyses. H-RK, YKC and S-KK provided feedback on the study design and analyses. HEL drafted the manuscript, and all authors participated in revising the manuscript and approved the final version.

\section{Competing interests None declared.}

Ethics approval The Institutional Review Board of Occupational Safety and Health Research Institute approved this study in 2012.

Provenance and peer review Not commissioned; externally peer reviewed.

Data sharing statement Data sharing will have to be requested from the ministry of labor and statistics after review of the IRB for this matter.

Open Access This is an Open Access article distributed in accordance with the Creative Commons Attribution Non Commercial (CC BY-NC 4.0) license, which permits others to distribute, remix, adapt, build upon this work non-commercially, and license their derivative works on different terms, provided the original work is properly cited and the use is non-commercial. See: http://creativecommons.org/ licenses/by-nc/4.0/

\section{REFERENCES}

1 Townsend P, Davidson N. Inequalities in health: the Black Report. Harmondsworth, UK: Penguin Books, 1982.

2 Jung-Choi K, Khang YH, Cho HJ. Changes in contribution of causes of death to socioeconomic mortality inequalities in Korean adults. J Prev Med Public Health 2011;44:249-59.

3 Jung-Choi K, Khang YH, Cho HJ. Socioeconomic differentials in cause-specific mortality among 1.4 million South Korean public servants and their dependents. $J$ Epidemiol Community Health 2011;65:632-8. 
4 Khang YH, Kim HR. Relationship of education, occupation, and income with mortality in a representative longitudinal study of South Korea. Eur J Epidemiol 2005;20:217-20.

$5 \mathrm{Kim} \mathrm{MH}$, Jung-Choi $\mathrm{K}$, Kim $\mathrm{H}$, et al. Educational inequality in female cancer mortality in Korea. J Korean Med Sci 2015;30:1-6.

6 Shim E, Cho Y. Widening social disparities in alcohol-attributable deaths among Korean men aged $40-59$ years during the transitional period of the economic crisis (1995-2005). Int J Public Health 2013:58:521-7.

7 Son M, Armstrong B, Choi JM, et al. Relation of occupational class and education with mortality in Korea. J Epidemiol Community Health 2002;56:798-9.

8 Lee H, Kim E, Kang S. 124 Differences of mortality rates by occupation in Korea: 14 years follow-up study. Occup Environ Med 2013;70(Suppl 1):A42.

9 Statistics Korea. Statistics of residence registration population. 2015. http://kosis.kr/ statHtml/statHtml.do?orgld=101\&tblld=DT_1B04005\&vw_cd=MT_ZTITLE\&list_

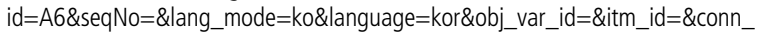
path $=$ E1\# (accessed 11 Dec 2015).

10 Davey Smith G, Hart C, Hole D, et al. Education and occupational social class: which is the more important indicator of mortality risk? J Epidemiol Community Health 1998:52:153-60.

11 Fujishiro K, Xu J, Gong F. What does "occupation" represent as an indicator of socioeconomic status?: exploring occupational prestige and health. Soc Sci Med 2010;71:2100-7.

12 Marmot MG, Smith GD, Stansfeld S, et al. Health inequalities among British civil servants: the Whitehall II study. Lancet 1991;337:1387-93.

13 Ministry of Employment and Labor. Survey on labor conditions by employment type 2013. 2015. http://kosis.kr/statisticsList/statisticsList_01List.jsp?vwcd=MT_ ZTITLE\&parentld=B\#SubCont (accessed 11 Dec 2015).

14 Zajacova A, Hummer RA. Gender differences in education effects on all-cause mortality for white and black adults in the United States. Soc Sci Med 2009;69:529-37.

15 Montez JK, Hayward MD, Brown DC, et al. Why is the educational gradient of mortality steeper for men? J Gerontol B Psychol Sci Soc Sci 2009;64:625-34.

16 Huisman $M$, Kunst $A E$, Bopp $M$, et al. Educational inequalities in cause-specific mortality in middle-aged and older men and women in eight western European populations. Lancet 2005;365:493-500.

17 Rosvall M, Chaix B, Lynch J, et al. Contribution of main causes of death to social inequalities in mortality in the whole population of Scania, Sweden. BMC Public Health 2006;6:79.

18 Mackenbach JP, Stirbu I, Roskam AJ, et al. Socioeconomic inequalities in health in 22 European countries. N Engl J Med 2008;358:2468-81.

19 Khang YH, Lynch JW, Jung-Choi K, et al. Explaining age-specific inequalities in mortality from all causes, cardiovascular disease and ischaemic heart disease among South Korean male public servants: relative and absolute perspectives. Heart 2008;94:75-82.

20 Strand BH, Groholt EK, Steingrimsdottir OA, et al. Educational inequalities in mortality over four decades in Norway: prospective study of middle aged men and women followed for cause specific mortality, 1960-2000. BMJ 2010;340:c654.

21 Ministry of Employment and Labor. Industrial accident statistics 2014. 2015. http:// laborstat.molab.go.kr/ (accessed 11 Dec 2015).
22 Marsh SM, Menendez CC, Baron SL, et al. Fatal work-related injuries-United States, 2005-2009. MMWR Surveill Summ 2013;62:S41-5.

23 Borrell C, Plasencia A, Huisman M, et al. Education level inequalities and transportation injury mortality in the middle aged and elderly in European settings. Inj Prev 2005;11:138-42.

24 Lorant $V$, Kunst $A E$, Huisman $M$, et al. Socio-economic inequalities in suicide: a European comparative study. Br J Psychiatry 2005;187:49-54.

25 Schneider B, Grebner K, Schnabel A, et al. Impact of employment status and work-related factors on risk of completed suicide. A case-control psychological autopsy study. Psychiatry Res 2011;190:265-70.

$26 \mathrm{Kim} \mathrm{MH}$, Jung-Choi $\mathrm{K}$, Jun $\mathrm{HJ}$, et al. Socioeconomic inequalities in suicidal ideation, parasuicides, and completed suicides in South Korea. Soc Sci Med 2010;70:1254-61.

27 Milner A, Spittal MJ, Pirkis J, et al. Suicide by occupation: systematic review and meta-analysis. Br J Psychiatry 2013;203:409-16.

28 Lee WJ, Cha ES, Moon EK. Disease prevalence and mortality among agricultural workers in Korea. J Korean Med Sci 2010;25:S112-8.

29 Chang SS, Lu TH, Sterne JA, et al. The impact of pesticide suicide on the geographic distribution of suicide in Taiwan: a spatial analysis. BMC Public Health 2012;12:260.

30 Park B, Choi KS, Lee HY, et al. Determinants of suboptimal hepatitis B vaccine uptake among men in the Republic of Korea: where should our efforts be focused: results from cross-sectional study. BMC Infect Dis 2013;13:218.

31 Chung GE, Yim JY, Kim D, et al. Seroprevalence of hepatitis A and associated socioeconomic factors in young healthy Korean adults. Gut Liver 2011;5: 88-92.

32 Kim EA, Lee HE, Kang SK. Occupational burden of cancer in Korea. Saf Health Work 2010;1:61-8.

33 Quaglia A, Lillini R, Mamo C, et al. Socio-economic inequalities: a review of methodological issues and the relationships with cancer survival. Crit Rev Oncol Hematol 2013;85:266-77

34 Kang M, Yoo KB, Park EC, et al. Factors associated with organized and opportunistic cancer screening: results of the Korea National Health and Nutrition Examination Survey (KNHANES) 2007-2011. Asian Pac J Cancer Prev 2014;15:3279-86.

35 Lorant $\mathrm{V}$, Deliège $\mathrm{D}$, Eaton $\mathrm{W}$, et al. Socioeconomic inequalities in depression: a meta-analysis. Am J Epidemiol 2003;157:98-112.

36 Campion J, Bhugra D, Bailey $\mathrm{S}$, et al. Inequality and mental disorders: opportunities for action. Lancet 2013;382:183-4.

37 Statistics Korea. Economically active population survey 2015. 2015. http://kosis.kr/ statHtml/statHtml.do?orgld=101\&tblld=DT_1DA7002\&vw_cd=MT_ZTITLE\&list_ $\mathrm{id}=\mathrm{B} 11$ \&seqNo $=\&$ lang_mode $=$ ko\&language $=$ kor\&obj_var_id $=\& i t m \_i d=\&$ conn path=E1 (accessed 11 Dec 2015).

38 Ministry of Foreign Affairs and Trade. Sixty years of Korean diplomacy. 2011. http:/l www.mofat.go.kr/state/publication/history60/20100201/11367_file_2009\% 20dip60_6.pdf (accessed 11 Dec 2015).

39 Dash SK, Behera BK, Patro S. Accuracy in certification of cause of death in a tertiary care hospital-a retrospective analysis. J Forensic Leg Med 2014;24:33-6.

40 Won TY, Kang BS, Im TH, et al. The study of accuracy of death statistics. J Korean Soc Emerg Med 2007;18:256-62. 


\section{Erratum: Mortality rates by occupation in Korea: a nationwide, 13-year follow up study}

Lee HE, Kim HR, Chung YK, et al. Mortality rates by occupation in Korea: a nationwide, 13-year follow up study. Occup Environ Med 2016;doi:10.1136/oemed-2015-103192

This letter contains an error in the calendar year of follow-up of the cohort. The correct follow-up period was 1995-2009. The affected text has been corrected to now read:

Mortality was determined by matching death between July 1995 and December 2009 according to a nationwide registry of the Korea National Statistical Office.

The cohort data set was sent to the Korea National Statistical Office (KNSO) for matching deaths between July 1995 and December 2009.

Occup Environ Med 2016;73:496. doi:10.1136/oemed-2015-103192corr1
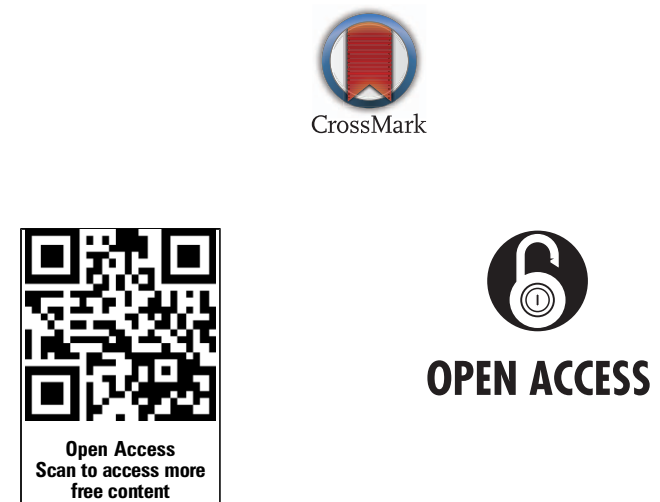

Open Access This is an Open Access article distributed in accordance with the Creative Commons Attribution Non Commercial (CC BY-NC 4.0) license, which permits others to distribute, remix, adapt, build upon this work non-commercially, and license their derivative works on different terms, provided the original work is properly cited and the use is noncommercial. See: http://creativecommons.org/licenses/by-nc/4.0/ 